\title{
Association analysis of formyl peptide receptor 2 (FPR2) polymorphisms and Aspirin exacerbated respiratory diseases
}

\author{
Hee-Jeong Kim ${ }^{1,9}$, Sung-Hwan Cho ${ }^{1,9}$, Jong-Sook Park ${ }^{1}$, Tae-Hyeong Lee ${ }^{1}$, Eun-Ju Lee ${ }^{1}$, Yong-Hoon Kim ${ }^{2}$, \\ Soo-Taek Uh ${ }^{3}$, Il Yup Chung ${ }^{4}$, Mi-Kyeong Kim ${ }^{5}$, Inseon S Choi ${ }^{6}$, Byung-Lae Park ${ }^{7,9}$, Hyoung-Doo Shin ${ }^{7,8}$ \\ and Choon-Sik Park ${ }^{1}$
}

Aspirin-exacerbated respiratory diseases (AERD) are associated with the metabolism of arachidonic acid. FPR2 (formyl peptide receptor2) is a high-affinity ligand receptor for potent anti-inflammatory lipid metabolites: lipoxins. Thus, functional alterations of the FPR2 may contribute to AERD. We investigated the relationship between single-nucleotide polymorphisms (SNPs) in the FPR2 and AERD. Asthmatics were categorized into AERD $<15 \%$ decreases in forced expiratory volume in one second $\left(\mathrm{FEV}_{1}\right)$, and/or naso-ocular reactions after oral aspirin challenge $(n=170)$ and aspirin-tolerant asthma (ATA, $n=268)$. In all, 11 SNPs were genotyped. FPR2 protein expressions on CD14-positive monocytes in peripheral blood were measured using flow cytometric analysis. We performed RT-PCR of the FPR2 mRNA expressed by peripheral blood mononuclear cells. Logistic regression analysis showed that the minor allele frequency of $F P R 2-4209 T>G$ (rs1769490) in intron 2 was significantly lower in the AERD group $(n=170)$ than in the ATA group $(n=268)\left(P=0.006, P^{c o r r}=0.04\right.$, recessive model). The decline of FEV $_{1}$ after aspirin challenge was significantly lower in the subjects with GG homozygotes of $F P R 2-4209 T>G$ than those with the other genotypes $(P=0.0002)$. Asthmatic homozygotes for $F P R 2-4209 T>G$ minor allele exhibited significantly higher $F P R 2$ protein expression in CD14-positive monocytes than did those with the common allele of $F P R 2-4209 T>G$ allele $(P=0.01)$. There was no difference in the expression of the wild form and the exon 2 deleted variant form of $F P R 2$ gene according to the genotypes of FPR2 $-4209 T>G$. The minor allele at FPR2 $-4209 T>G$ may have a protective role against the development of AERD, via increase of $F P R 2$ protein expression in inflammatory cells.

Journal of Human Genetics (2012) 57, 247-253; doi:10.1038/jhg.2012.12; published online 1 March 2012

Keywords: aspirin; asthma; FPR2 (formyl peptide receptor 2); SNPs (single-nucleotide polymorphisms)

\section{INTRODUCTION}

Aspirin-exacerbated respiratory diseases (AERD) refer to the development of bronchoconstriction in asthmatic individuals following the ingestion of aspirin (acetylsalicylic acid) or other non-steroidal antiinflammatory drugs. This syndrome is characterized by the 'aspirin triad,' which consists of aspirin hypersensitivity, bronchial asthma, nasal polyposis and chronic hyperplastic eosinophilic sinusitis. ${ }^{1-3}$ Similar to other asthmatic individuals, the airways of patients with AERD show signs of persistent inflammation with marked eosinophilia, epithelial disruption, cytokine production and upregulation of inflammatory molecules. ${ }^{4}$ Overproduction or underproduction of critical modulators important for the metabolism of arachidonic acids, including leukotrienes, lipoxins, thromboxane and prostaglandins, likely accounts for the observed susceptibility to aspirin. Variations within the genes of the arachidonate pathway are responsible for changes in the production and metabolism of these modulators. Polymorphisms in genes such as LTC $4 S,{ }^{5}$ ALOX $5,{ }^{6}$ PTGER $2,{ }^{7}$ PTGER $3,{ }^{8}$ CYSLTR $2,{ }^{9}$ TBXA2R ${ }^{10}$ and CYSLTR $1{ }^{11}$ have previously been shown to be associated with AERD. Among the proteins encoded by these genes, the cysteinyl leukotriene (CysLT) receptor is selectively

${ }^{1}$ Genome Research Center for Allergy and Respiratory Disease, Soonchunhyang University Bucheon Hospital, Wonmi-gu, Bucheon, Republic of Korea; ${ }^{2}$ Division of Allergy and Respiratory Medicine, Soonchunhyang University Cheonan Hospital, Bongmyeong-dong, Cheonan, Korea; ${ }^{3}$ Division of Allergy and Respiratory Medicine, Soonchunhyang University Seoul Hospital, Daesagwan-gil, Yongsan-Gu, Seoul, Republic of Korea; ${ }^{4}$ Division of Molecular and Life Sciences, College of Science and Technology, Hanyang University, Ansan, Republic of Korea; ${ }^{5}$ Division of Internal Medicine, Chungbuk National University, College of Medicine, Cheongju, Republic of Korea; ${ }^{6}$ Department of Allergy, Chonnam National University Medical School and Research Institute of Medical Sciences, Gwangju, Republic of Korea; ${ }^{7}$ Department of Genetic Epidemiology, SNP Genetics Inc., Seoul, Republic of Korea and ${ }^{8}$ Department of Life Science, Sogang University, Seoul, Republic of Korea

${ }^{9}$ Equally contributed as the first authors.

Correspondence: Dr Choon-Sik Park, Division of Allergy and Respiratory Medicine, Department of Internal Medicine, Soonchunhyang University Bucheon Hospital, 1174 , Jung Dong, Wonmi Ku, Bucheon, Gyeonggi Do, 420-021, Republic of Korea.

E-mail: mdcspark@unitel.co.kr

or Dr H-D Shin, Department of Life Science, Sogang University, 1 Shinsu-dong, Mapo-gu, Seoul, 121-742, Republic of Korea.

E-mail: hdshin@sogang.ac.kr

Received 3 November 2011; revised 22 December 2011; accepted 12 January 2012; published online 1 March 2012 
antagonized by several currently available leukotriene modifiers, including montelukast, pranlukast and zafirlukast. However, clinical studies have demonstrated that the response to these medications is incomplete. ${ }^{12,13}$ These results suggest that an alternative pathway that does not include CysLT or the CystLT receptor may lead to aspirin hypersensitivity in asthma.

Both LXA4 and aspirin- triggered 15-epi lipoxin 4 (ATL) serve as 'stop' signals for leukocyte trafficking, facilitating the resolution of inflammatory responses. ${ }^{14,15}$ These responses are mediated by formyl peptide receptor 2 (FPR2, also known as FPRL1, ALXR, HM63, FMLPX, FPR2A, FPRH1 and FPRH2), which is the surface membrane seven-transmembrane G-protein-coupled receptors. FPR2 is expressed by various kinds of inflammatory cells, including macrophages, monocytes, neutrophils, $\mathrm{T}$ lymphocytes, bronchial epithelial cells and microvascular endothelial cells. ${ }^{16,17}$ These inflammatory cells are involved in the pathogenesis of asthma and in asthmatic subphenotypes, including aspirin hypersensitivity. On the basis of these biological functions, genetic alterations in FPR2 may be postulated to contribute to the pathophysiological processes of AERD. However, a comprehensive genetic analysis of FPR2 in patients with AERD has not been performed to date. To investigate the genetic role of FPR2 in AERD, we identified single-nucleotide polymorphisms (SNPs) of the FPR2 and performed genetic association analyses and functional validation studies to determine the association between the alterations in FPR2 with the risk of AERD.

\section{MATERIALS AND METHODS}

\section{Subjects and aspirin challenge}

Subjects were recruited from the Asthma Genome Research Center, which is comprised of nine university hospitals in Korea. All subjects were Korean. All patients were diagnosed by physicians based on the definition of asthma by the Global Initiative for Asthma guidelines. ${ }^{18}$ All patients had a history of dyspnea and wheezing during the previous 12 months and also met one of the following criteria: (1) $>15 \%$ increase in forced expiratory volume in one second $\left(\mathrm{FEV}_{1}\right)$ or $>12 \%$ increase plus $200 \mathrm{ml}$ following inhalation of a short-acting bronchodilator, (2) $<10 \mathrm{mg} \mathrm{ml}^{-1}$ PC20 methacholine and (3) $>20 \%$ increase in $\mathrm{FEV}_{1}$ following 2 weeks of treatment with inhaled steroids and long-acting bronchodilators. A total of 24 common inhalant allergens were utilized for a skin prick test. Atopy was defined as having a wheal reaction equal to or greater than $3 \mathrm{~mm}$ in diameter or than that of histamine. Total IgE was measured using the CAP system (Pharmacia Diagnostics, Uppsala, Sweden).
Asthmatic patients had experienced no exacerbation of asthma or respiratory tract infection in the 6 weeks preceding oral aspirin challenge. Oral aspirin challenge was performed with increasing doses of aspirin using methods slightly modified from those described previously. ${ }^{2,19}$ Briefly, the patient having history of aspirin hypersensitivity was given $30 \mathrm{mg}$ and those having no history started $100 \mathrm{mg}$ of aspirin orally. Respiratory and naso-ocular symptoms, blood pressure, external signs (urticaria and angio-oedema) and $\mathrm{FEV}_{1}$ were documented every $30 \mathrm{~min}$ for a period of $1.5 \mathrm{~h}$. In the absence of any symptoms or signs suggestive of adverse reaction, $60 \mathrm{mg}$ or $100 \mathrm{mg}$ of aspirin was administered and the same measurements were repeated every $1 \mathrm{~h}$, with a final dose of $450 \mathrm{mg}$ or until the patient developed a reaction. If no reaction occurred $4 \mathrm{~h}$ after the final dose, the test was deemed negative. Aspirin-induced bronchospasms, reflected by decline $(\%)$ of $\mathrm{FEV}_{1}$, were calculated as the pre-challenge $\mathrm{FEV}_{1}$ minus the post-challenge $\mathrm{FEV}_{1}$ divided by the pre-challenge $\mathrm{FEV}_{1}$. Oral aspirin challenge reactions were categorized into two groups as follows: (1) 15\% or greater decrease in $\mathrm{FEV}_{1}$ and/or naso-ocular reactions (AERD) or (2) less than $15 \%$ decrease in $\mathrm{FEV}_{1}$ without naso-ocular or cutaneous reactions (aspirin tolerant asthma (ATA)). The ethics committee at each hospital approved the protocols and a written informed consent was obtained from all patients.

\section{Genotyping of FPR2 polymorphisms}

In all, 11 polymorphisms found in the FPR2 in the National Center for Biotechnology Information (Build 36) were selected for this study, and amplification and extension primers were designed for genotyping each of the polymorphic sites by single-base extension..$^{20}$ All primer extension reactions were performed using the SNaPshot ddNTP Primer Extension Kit (Applied Biosystems, Foster City, CA, USA). Following the extension reaction, the reaction mixtures were incubated at $37^{\circ} \mathrm{C}$ for $1 \mathrm{~h}$ with $1 \mathrm{U}$ of shrimp alkaline phosphatase, followed by incubation for $15 \mathrm{~min}$ at $72{ }^{\circ} \mathrm{C}$ to inactivate the enzyme. The extension products and Geescan 120 Liz size standard solution were then mixed with $\mathrm{Hi}$-Di formamide according to the manufacturer's instructions and incubated at $95^{\circ} \mathrm{C}$ for $5 \mathrm{~min}$, followed by $5 \mathrm{~min}$ on ice. The products of the reaction mixture were resolved using an ABI Prism 3100 Genetic Analyzer (Applied Biosystems). Results were analyzed using GeneScan and Genotyper (Applied Biosystems). Primer sequences are shown in Supplementary Table 1. For quality control for genotyping, 16 blank and 16 duplicate were used, and the concordance rate was $100 \%$ in this study.

\section{Measurement of FPR2 protein expression on CD14-positive monocytes of asthmatics}

Peripheral blood mononuclear cells (PBMC) were purified from the heparinized peripheral blood of the study subjects by using a density gradient reagent (Histopaque 1077). FITC-conjugated anti-rabbit antibody (BD Pharmingen,

Table 1 Clinical profile of aspirin-exacerbated respiratory diseases (AERD) and aspirin-tolerant asthma (ATA)

\begin{tabular}{|c|c|c|c|}
\hline Clinical profile & $A E R D$ & ATA & $\mathrm{P}$-value \\
\hline$N$ & 170 & 268 & \\
\hline Onset of age (mean (range)) & $36(10-66)$ & $40(8-72)$ & 0.002 \\
\hline Sex (male/female) & $62 / 108$ & $87 / 181$ & NS \\
\hline Current Smoker/Ex smoker (\%) & $8.82 / 13.53$ & $17.54 / 15.67$ & 0.02 \\
\hline $\mathrm{BMI}\left(\mathrm{kg} \mathrm{m}^{-2}\right)$ & $23.69 \pm 3.29$ & $24.56 \pm 3.52$ & 0.01 \\
\hline FVC (\%), predicted & $90.37 \pm 14.59$ & $87.83 \pm 14.90$ & NS \\
\hline $\mathrm{FEV}_{1}(\%)$, predicted & $87.12 \pm 17.44$ & $89.75 \pm 18.46$ & NS \\
\hline PC20, methacholine $\left(\mathrm{mg} \mathrm{ml}^{-1}\right)$ & $4.86 \pm 7.90$ & $2.79 \pm 3.34$ & NS \\
\hline Atopy (\%) & $50.91 \%$ & $56.34 \%$ & NS \\
\hline Total IgE (IU ml-1) & $355.40 \pm 615.90$ & $353.31 \pm 561.73$ & NS \\
\hline Blood eosinophil (\%) & $5.84 \pm 5.13$ & $6.22 \pm 5.61$ & NS \\
\hline Decline of $\mathrm{FEV}_{1}$ after OAC (\%) & $24.77 \pm 16.33$ & $3.48 \pm 4.52$ & $<0.0001$ \\
\hline History of aspirin hypersensitivity (\%) & 39.41 & 6.06 & $<0.0001$ \\
\hline
\end{tabular}

Abbreviations: $\mathrm{BMI}$, body mass index; $\mathrm{FEV}_{1}$, forced expiratory volume in one second; FVC, forced vital capacity; NS, non-significant difference; OAC, oral aspirin challenge; PC20, provocative concentration of 20 total in $\mathrm{FEV}_{1}$

Data are presented as mean \pm s.e.

$P$ values are obtained using $t$-test or $\chi^{2}$-test between group with AERD and ATA. 
San Diego, CA, USA), FPR2 antibody (Abcam, Cambridge, UK) and phycoerythrin (PE)-conjugated anti-human CD14 antibody (R\&D Systems, Minneapolis, MN, USA) were incubated with $5 \times 10^{5} \mathrm{cell} \mathrm{ml}^{-1} \mathrm{PBMC}$ and then washed twice with PBS. The stained cells were analyzed by using a flow cytometer (FACScan; Becton-Dickinson, Mountain View, CA, USA). For isotype-matched controls, FITC-conjugated Rabbit IgG (Abcam) and PE-conjugated mouse IgG1 isotype ( $R \& D$ Systems) were used with the same concentration of each antibody tested. The stained cells were analyzed by using a flow cytometer (FACScan; Becton-Dickinson) and Cell Quest Software (Counter Corporation, Miami, FL, USA). Levels of FPR2 protein expression are monocyte X-mean FPR2/Isotype. Percentage of CD14 $(+)$ monocytes is monocyte gate\% FPR2-Isotype.

\section{RNA extraction and RT-PCR of FPR 2 mRNA}

Total RNA of PBMC was isolated using the modified guanidium thiocyanatephenol-chloroform extraction method. We quantified RNA and reverse transcribed cDNA from $3 \mu \mathrm{g}$ of total RNA. DNase I ( $10000 \mathrm{U} \mathrm{ml}^{-1}$; Stratagene, La Jolla, CA, USA)-treated RNA was reverse-transcribed by incubating with $0.5 \mathrm{~mm}$ dNTP, $2.5 \mathrm{~mm} \mathrm{MgCl} 2,5 \mathrm{~mm}$ DTT, $1 \mu \mathrm{l}$ of random hexamer $\left(50 \mu \mathrm{gl}^{-1}\right)$

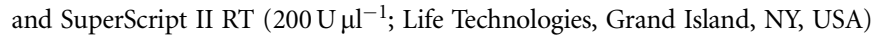
at $42^{\circ} \mathrm{C}$ for $50 \mathrm{~min}$, and heat inactivated at $70{ }^{\circ} \mathrm{C}$ for $15 \mathrm{~min}$. Specific primer pairs for RT-PCR were as follows GAPDH forward; $5^{\prime}$-ACCCAGAAGACTGTG GATGG-3', GAPDH reverse; 5'-TTCTAGACGGCAGGTCAGGT-3' and FPR2 forward; 5'-GCACACAGGAAAAGGAGCTT-3', FPR2 reverse; and 5'-ACAGAT GGTGGTGACTGTGC- $3^{\prime}$. Amplification was performed for 35 cycles (one cycle: $30 \mathrm{~s}$ at $94^{\circ} \mathrm{C}, 30 \mathrm{~s}$ at $55^{\circ} \mathrm{C}$ and $40 \mathrm{~s}$ at $72{ }^{\circ} \mathrm{C}$ ) with initial denaturation at $94{ }^{\circ} \mathrm{C}$ for $5 \mathrm{~min}$ and a final extension at $72{ }^{\circ} \mathrm{C}$ for $10 \mathrm{~min}$. The size and amount of the PCR products generated were determined by agarose gel electrophoresis in the presence of ethidium bromide and analyzed with the Kodak EDAS 1D analysis package. The sequence of RT-PCR products was determined using the BLAST search program after direct sequencing.

Table 2 Logistic analysis for the risk of aspirin intolerance associated with FPR2 polymorphisms controlled for age, sex, atopy, smoking status and BMI in Korean asthmatics

\begin{tabular}{|c|c|c|c|c|c|c|c|c|c|c|c|c|c|c|}
\hline \multirow[b]{2}{*}{ Loci } & \multirow[b]{2}{*}{ rs number } & \multirow[b]{2}{*}{ Position } & \multirow[b]{2}{*}{ Genotype } & \multicolumn{2}{|c|}{$N(\%)$} & \multicolumn{3}{|c|}{ Codominant } & \multicolumn{3}{|c|}{ Dominant } & \multicolumn{3}{|c|}{ Recessive } \\
\hline & & & & AIA & ATA & OR $(95 \% \mathrm{Cl})$ & $\mathrm{P}$ & $P^{\text {corr }}$ & OR $(95 \% \mathrm{Cl})$ & $\mathrm{P}$ & $P^{c o r r}$ & OR $(95 \% \mathrm{Cl})$ & $\mathrm{P}$ & $P^{\text {corr }}$ \\
\hline \multirow[t]{3}{*}{$-5840 \mathrm{G}>\mathrm{T}$} & rs4801893 & Intron1 & GG & $48(29.6 \%)$ & $60(22.4 \%)$ & & & & & & & & & \\
\hline & & & GT & $82(50.6 \%)$ & $144(53.7 \%)$ & $0.83(0.62-1.11)$ & 0.21 & 1 & $0.75(0.48-1.20)$ & 0.23 & 1 & $0.81(0.50-1.33)$ & 0.40 & 1 \\
\hline & & & TT & 32 (19.8\%) & 64 (23.9\%) & & & & & & & & & \\
\hline \multirow[t]{3}{*}{$-4351 A>C$} & rs10853843 & Intron1 & AA & 145 (90.1\%) & $238(89.5 \%)$ & & & & & & & & & \\
\hline & & & $A C$ & $16(9.9 \%)$ & 28 (10.5\%) & $0.98(0.50-1.91)$ & 0.94 & 1 & $0.98(0.50-1.91)$ & 0.94 & 1 & & . & . \\
\hline & & & $\mathrm{CC}$ & $0(0 \%)$ & $0(0 \%)$ & & & & & & & & & \\
\hline \multirow[t]{3}{*}{$-4209 T>G$} & rs17694990 & Intron1 & TT & $86(53.4 \%)$ & $122(45.7 \%)$ & & & & & & & & & \\
\hline & & & $\mathrm{TG}$ & $68(42.2 \%)$ & 109 (40.8\%) & $0.67(0.49-0.93)$ & 0.02 & 0.11 & $0.73(0.49-1.10)$ & 0.13 & 0.91 & $0.30(0.13-0.71)$ & 0.006 & 0.04 \\
\hline & & & GG & $7(4.4 \%)$ & $36(13.5 \%)$ & & & & & & & & & \\
\hline \multirow[t]{3}{*}{$-2940 \mathrm{C}>\mathrm{T}$} & rs4802863 & Intron1 & $\mathrm{CC}$ & $86(53.1 \%)$ & $122(45.7 \%)$ & & & & & & & & & \\
\hline & & & CT & $68(42.0 \%)$ & 109 (40.8\%) & $0.69(0.50-0.95)$ & 0.02 & 0.16 & $0.75(0.50-1.12)$ & 0.16 & 1 & $0.34(0.15-0.78)$ & 0.01 & 0.07 \\
\hline & & & $\mathrm{TT}$ & $8(4.9 \%)$ & $36(13.5 \%)$ & & & & & & & & & \\
\hline \multirow[t]{3}{*}{$-1825 C>G$} & rs17834679 & Intron1 & $\mathrm{CC}$ & $62(38.3 \%)$ & $123(45.9 \%)$ & & & & & & & & & \\
\hline & & & CG & $72(44.4 \%)$ & $114(42.5 \%)$ & $1.28(0.95-1.71)$ & 0.10 & 0.69 & $1.34(0.89-2.02)$ & 0.17 & 1 & $1.47(0.83-2.61)$ & 0.19 & 1 \\
\hline & & & GG & $28(17.3 \%)$ & 31 (11.6\%) & & & & & & & & & \\
\hline \multirow[t]{3}{*}{$-1750 \mathrm{~T}>\mathrm{C}$} & rs17695020 & Intron1 & TT & 135 (83.3\%) & $218(82.0 \%)$ & & & & & & & & & \\
\hline & & & TC & 27 (16.7\%) & $43(16.2 \%)$ & $0.78(0.47-1.30)$ & 0.34 & 1 & $0.84(0.49-1.45)$ & 0.53 & 1 & & & \\
\hline & & & $\mathrm{CC}$ & $0(0.0 \%)$ & $5(1.9 \%)$ & & & & & & & & & \\
\hline \multirow[t]{3}{*}{$-1365 G>A$} & rs17756793 & Intron1 & GG & $135(83.3 \%)$ & $218(81.3 \%)$ & & & & & & & & & \\
\hline & & & $\mathrm{GA}$ & 27 (16.7\%) & $45(16.8 \%)$ & $0.77(0.46-1.27)$ & 0.30 & 1 & $0.82(0.48-1.41)$ & 0.47 & 1 & & & \\
\hline & & & $\mathrm{AA}$ & $0(0.0 \%)$ & $5(1.9 \%)$ & & & & & & & & & \\
\hline \multirow[t]{3}{*}{$-970 \mathrm{~T}>\mathrm{C}$} & rs17695032 & Intron1 & $\mathrm{TT}$ & 135 (83.3\%) & $221(82.5 \%)$ & & & & & & & & & \\
\hline & & & $\mathrm{TC}$ & 27 (16.7\%) & $42(15.7 \%)$ & $0.80(0.48-1.33)$ & 0.39 & 1 & $0.86(0.50-1.49)$ & 0.60 & 1 & & & \\
\hline & & & $\mathrm{CC}$ & $0(0.0 \%)$ & $5(1.9 \%)$ & & & & & & & & & \\
\hline \multirow[t]{3}{*}{$-894 C>A$} & rs17756805 & Intron1 & $\mathrm{CC}$ & $135(83.3 \%)$ & $218(81.3 \%)$ & & & & & & & & & \\
\hline & & & $\mathrm{CA}$ & $27(16.7 \%)$ & 45 (16.8\%) & $0.76(0.46-1.25)$ & 0.28 & 1 & $0.81(0.47-1.39)$ & 0.44 & 1 & & & \\
\hline & & & AA & $0(0.0 \%)$ & $5(1.9 \%)$ & & & & & & & & & \\
\hline \multirow[t]{3}{*}{$-421 A>G$} & rs17756817 & Intron1 & $\mathrm{AA}$ & $135(83.3 \%)$ & $219(82.0 \%)$ & & & & & & & & & \\
\hline & & & $A G$ & 27 (16.7\%) & $42(15.7 \%)$ & $0.77(0.47-1.28)$ & 0.32 & 1 & $0.84(0.49-1.45)$ & 0.54 & 1 & & . & \\
\hline & & & GG & $0(0.0 \%)$ & $6(2.3 \%)$ & & & & & & & & & \\
\hline \multirow[t]{3}{*}{$+1315 A>G$} & rs17695052 & Exon2 & AA & 135 (83.3\%) & 217 (81.6\%) & & & & & & & & & \\
\hline & & & $A G$ & 27 (16.7\%) & $44(16.5 \%)$ & $0.77(0.46-1.27)$ & 0.31 & 1 & $0.82(0.48-1.42)$ & 0.48 & 1 & & & \\
\hline & & & GG & $0(0.0 \%)$ & $5(1.9 \%)$ & & & & & & & & & \\
\hline \multirow[t]{3}{*}{ ht2 } & & & $-1-$ & $70(43.2 \%)$ & $119(44.4 \%)$ & & & & & & & & & \\
\hline & & & ht2/- & $72(44.4 \%)$ & $123(45.9 \%)$ & $1.11(0.82-1.51)$ & 0.49 & 1 & $1.10(0.73-1.65)$ & 0.66 & 1 & $1.29(0.68-2.44)$ & 0.44 & 1 \\
\hline & & & ht2/ht2 & $20(12.4 \%)$ & $26(9.7 \%)$ & & & & & & & & & \\
\hline \multirow[t]{3}{*}{ ht3 } & & & $-1-$ & 109 (67.3\%) & $163(60.8 \%)$ & & & & & & & & & \\
\hline & & & ht3/- & $49(30.3 \%)$ & $85(31.7 \%)$ & $0.74(0.52-1.05)$ & 0.09 & 0.64 & $0.78(0.51-1.20)$ & 0.26 & 1 & $0.33(0.11-1.02)$ & 0.05 & 0.37 \\
\hline & & & ht3/ht3 & $4(2.5 \%)$ & $20(7.5 \%)$ & & & & & & & & & \\
\hline
\end{tabular}

Abbreviations: AIA, aspirin induced asthma; ATA, aspirin-tolerant asthma; BMI, body mass index; CI, confidence interval; FPR2, formyl peptide receptor2; OR, odds ratio.

Logistic regression analyses were used to calculate the odds ratio and $p$-values of the codominant model, controlling for age (continuous value), sex (male $=0$, female $=1$ ), atopy status

(non-atopy $=0$, atopy $=1$ ), BMI (continuous value) and smoking status (non-smoker=0, ex-smoker $=1$, smoker=2) as co-variables 


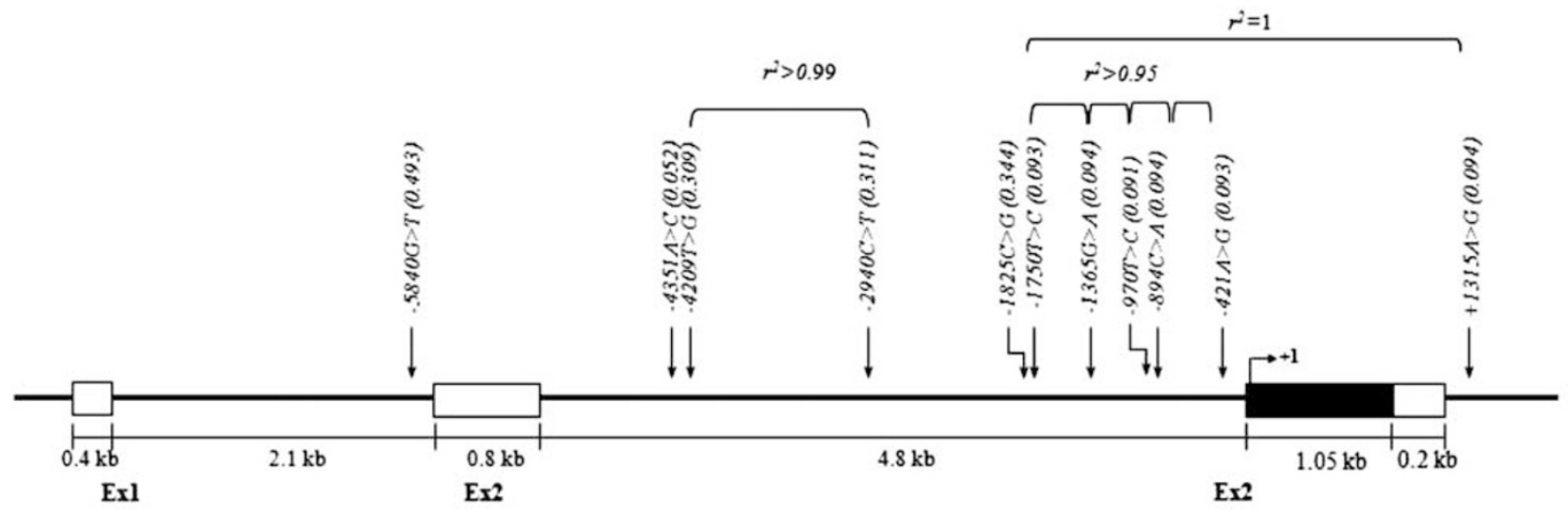

b

$$
\text { Haplotypes in FPR2 }
$$

c

LDs among FPR2 polymorphisms
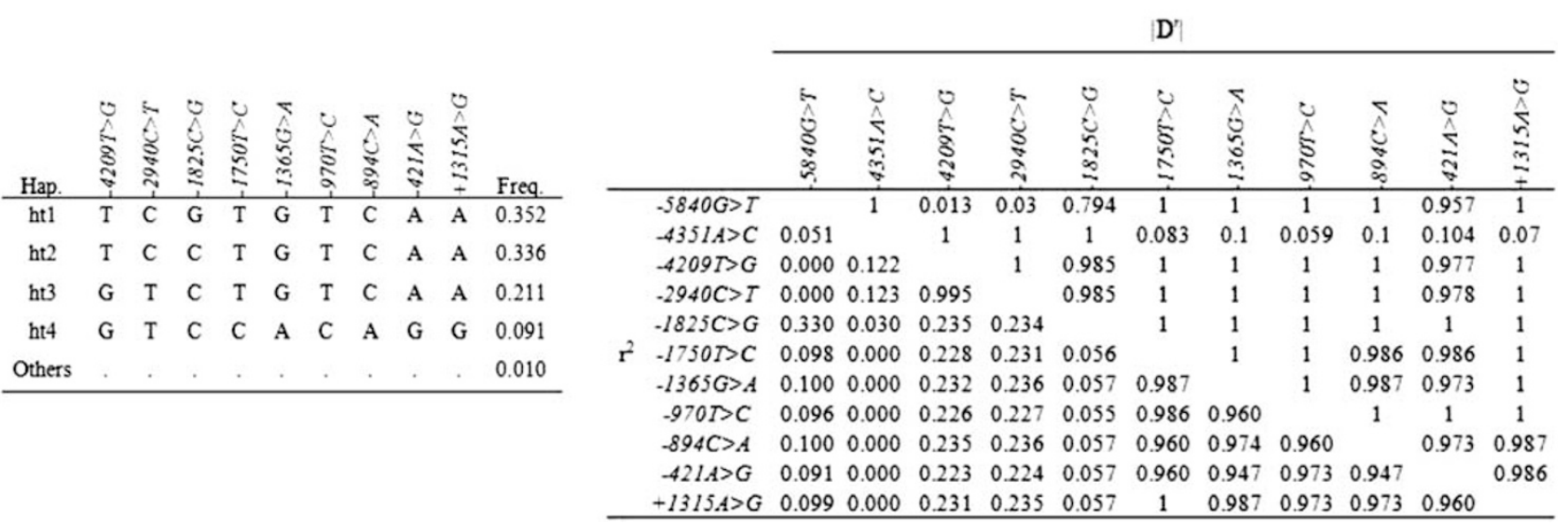

Figure 1 Gene map indicating haplotypes of the formyl peptide receptor2 (FPR2). (a) Gene map and single-nucleotide polymorphisms (SNPs) of FPR2, located on chromosome 19q13.3-q13.4. Coding exons are indicated by black blocks, and the $5^{\prime}$ and $3^{\prime}$-untranslated regions (UTRs) by white blocks. The base at which translation begins was denoted as nucleotide +1 . (b) FPR2 haplotypes. (c) Linkage disequilibrium coefficients (ID'l and $r^{2}$ ) among FPR2 SNPs.

\section{Statistical analysis}

We applied two widely used measures of linkage disequilibrium to all pairs of biallelic loci: Lewontin's $D^{\prime}\left(\left|D^{\prime}\right|\right)^{21}$ and $r^{2}$. Haplotypes for each individual were inferred using the PHASE algorithm (ver. 2.0), developed by Stephens et al..$^{22}$ Genotype and haplotype distributions were analyzed using logistic models with age (continuous value), gender (male $=0$, female $=1$ ), smoking status (nonsmoker $=0$, ex-smoker $=1$, smoker $=2)$, atopy $($ absence $=0$, presence $=1)$ and $\mathrm{BMI}$ as covariates. Differences in the decline of $\mathrm{FEV}_{1}$ following aspirin challenge among the genotypes were examined using independent $t$-test. Statistical data were managed and analyzed using SAS version 9.1 (SAS, Inc., Cary, NC, USA) and SPSS version 11.0 (SPSS, Inc., Chicago, IL, USA). To correct $P$-values, the effective number of independent markers in FPR2 was calculated using SNPSpD software (http://genepi.qimr.edu.au/general/daleN/SNPSpD). ${ }^{23}$ This program is based on the spectral decomposition of matrices of pairwise linkage disequilibrium between SNPs ( $P$-value X 6.7767). Corrected $P$-values less than 0.05 were regarded as being statistically significant. Intergroup comparisons of FPR2 expression were assessed by the non-parametric Kruskal-Wallis $H$-test for continuous data. If differences were found to be statistically significant, MannWhitney $U$-test was applied to analyze differences between the two groups. The FPR2 protein expressions are expressed as the mean \pm s.e. of the mean (s.e.m.).

$P$-values less than 0.05 were regarded as being statistically significant.

\section{RESULTS}

Characteristics of the study subjects

A total of 438 subjects were recruited from the asthma cohort. The clinical characteristics of the study subjects are summarized in Table 1.
Significant differences in onset age of asthma, prevalence of smoking and BMI were found between the AERD and the ATA groups $\left(P<0.05\right.$, Table 2). Aspirin-induced declines in $\mathrm{FEV}_{1}$ of -15 to $68 \%$ were observed.

Frequencies and haplotype construction of FPR2 polymorphisms In all, 11 polymorphic SNPs in the FPR2 gene were selected in the National Center for Biotechnology Information SNP database (NCBI SNP DB; build 36). In build 36 of NCBI SNP DB, there were no SNPs in exon 1 and 2 (Figure 1a). The minor allele frequencies of the 11 SNPs in the study subjects are summarized in Supplementary Table 2. The distributions of all loci were in Hardy-Weinberg equilibrium $(P>0.05)$. The linkage disequilibrium coefficients $\left(\left|D^{\prime}\right|\right)$ and $r^{2}$ for the FPR2 polymorphisms were calculated for all study subjects (Figure 1c). Absolute linkage disequilibrium $\left(\left|D^{\prime}\right|=1\right.$ and $\left.r^{2}=1\right)$ was present between $-1750 T>C$ and $+1315 A>G$. Tight linkages were also observed between $-4209 T>G$ and $-2940 C>\mathrm{T}\left(r^{2}>0.99\right)$, and among $-1750 T>C,-1365 G>A$, $-970 T>C,-894 C>A$ and $-421 A>G\left(r^{2}>0.95\right)$. Ten haplotypes were constructed from the 11 SNPs. Among these haplotypes, FPR2ht 2 and FPR2-ht3 (frequency $>0.05$ ) were used for analysis, because FPR2-ht1 and FPR2-ht4 were almost tagged with $-1825 C>G$ and $-1750 T>C$, respectively. 


\section{Association of FPR2 polymorphisms with the risk of aspirin} intolerance in asthmatics

All of the single SNPs and two haplotypes (ht2 and ht3) were analyzed for association with the risk of AERD using logistic models (Table 2). Association analysis revealed that two SNPs, FPR2 $-4209 T>G$ and $-2940 C>T$, were significantly associated with AERD in the recessive model ( $P=0.006$ and 0.01$)$. The other SNPs and haplotypes and haplotypes were not associated with the risk of AERD. After correction for multiple comparisons, the significant difference remained only for FPR2 $-4209 T>G\left(P^{c o r r}=0.04\right)$. The frequency of the homozygous GG genotype for FPR2 - 4209T $>G$ was three times lower in AERD patients, a significant difference from ATA patients $(4.4 \%$ and $13.5 \%$, respectively).

Differences in the rates of FEV1 decline following aspirin challenge among the genotypes and haplotypes were examined using multiple regression models (Figure 2). Asthmatics homozygous for the minor allele of FPR2 $-4209 T>G$ exhibited a lower decline in $\mathrm{FEV}_{1}$ induced by aspirin provocation than did heterozygotes and homozygotes carrying the common allele (11.66 $\pm 0.76 \%$ vs $6.24 \pm 1.19 \%$, $P=0.0002$, Figure 2).

Comparison of FPR2 protein expression between FPR2 - 4209T $>$ G genotypes using flow cytometry

To determine whether the sequence variants of FPR2 -4209T>G affected expression of the FPR2 protein, we measured FPR2 expression in CD14-positive (CD14 (+)) monocytes by flow cytometry (Figure 3a and $b$ ). FPR2 protein expression was measured in those obtained from asthmatics with the following genotypes: FPR2 -4209TT ( $n=26)$, FPR2 -4209GG $(n=6)$ and FPR2 -4209TG $(n=27)$. FPR2 expression in CD14 ( + monocytes was significantly different among the three groups $(P=0.021)$. The CD14 $(+)$ monocytes from asthmatic patients homozygous for the minor allele of $-4209 T>G(G G)$ exhibited a twofolds higher intensity of fluorescence stain for FPR2 protein than did those from patients having the common allele, FPR2 $-4209 T$ $(69.41 \pm 22.16$ vs $27.91 \pm 2.24$, respectively; $P=0.01$, Figure $3 \mathrm{c})$. More than $80 \%$ CD14 (+) monocytes expressed the FPR2 protein on their surface regardless of the genotypes of FPR2 $-4209 T>G$ (Figure 3d).

\section{Comparison of FPR2 mRNA expression between FPR2 - 4209T $>$ G genotypes}

To investigate the genetic effect of $-4209 T>G$ polymorphism on the alternative splicing of FPR2 on PBMC, RT-PCR for the FPR2 mRNA was performed. As FPR2 $-4209 T>G$ is located in the intron 2, we amplified mRNA containing FPR2 using primers to detect alternative splicing as described in methods and Figure 4a. We identified a wild-form (upper band, $360 \mathrm{bp}$ ) and an alternative form of FPR2 (lower band, $231 \mathrm{bp}$ ) (Figure 4b). The wild and the variant forms were similarly found in the RT-PCR products on mRNA from PBMC of the subjects having $-4209 G G$ or those having $-4209 T T$. The sequence of RT-PCR products was determined using the BLAST search program after direct sequencing. The alternative form was a variant deleted of exon 2 of 129 bp. (Figure 4c).

\section{DISCUSSION}

In the present study, we are the first, to the best of our knowledge, to identify a SNP located in the intron of FPR2 that is related to aspirin hypersensitivity in asthmatics. This association was characterized using a case-control association study, followed by functional validation of protein expression. The minor allele frequency of FPR2 $-4209 T>G$ significantly differed between the AERD and ATA groups, even after correction for multiple comparisons. Few studies have

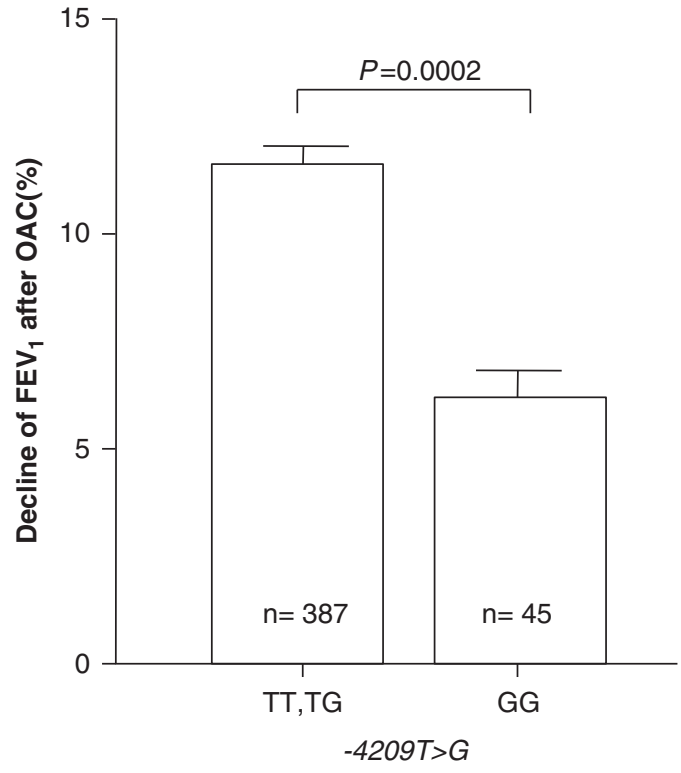

Figure 2 Comparison of the decline of forced expiratory volume in one second (FEV1) (\%) induced by aspirin provocation between subjects possessing different alleles of FPR2: $-4209 T>G$. $P$-values were obtained by linear regression analysis, controlled for age (continuous value), sex (male $=0$, female $=1$ ), atopy status (non-atopy $=0$, atopy $=1$ ), smoking status (non-smoker $=0$, ex-smoker $=1$, smoker $=2$ ) and body mass index $(B M I)$ as co-variables.

explored the association of FPR2 polymorphisms with human disease. In a previous association study of FPR2 genetic variants, two SNPs (F110S and $\mathrm{C} 126 \mathrm{~W})$, located in the open reading frame of FPR2, were found to be associated with juvenile periodontitis. ${ }^{24}$ These SNPs were not analyzed in our study, because the design of this study was based on the NCBI DB and these two SNPs were not in NCBI DB. These SNPs were not analyzed in the present study. We found that asthmatics homozygous for the FPR2 $-4209 T>G$ minor allele exhibited a lower $\mathrm{FEV}_{1}$ decline after aspirin challenge than patients who were heterozygous or homozygous for the common allele. These data indicate that the minor allele of FPR2 -4209T > G may protect against the development of aspirin-induced bronchospasms in asthmatics.

As the FPR2 was initially cloned based on homology to the FPR CDNA, ${ }^{25,26}$ the importance of FPR in the host defense against bacterial infections has been demonstrated by the increased susceptibility of Fpr2 knockout mice to Listeria monocytogenes. ${ }^{27}$ Additionally, the FPR2 has been demonstrated to have novel roles for lipoxin and aspirin-triggered lipoxin in the regulation of T-cell-mediated responses. The lipoxin and aspirin-triggered lipoxin inhibit TNF-alpha secretion from activated $\mathrm{T}$ cells via the FPR2. ${ }^{28}$ In previous functional studies, transcription of FPR2 was shown to be dramatically upregulated by IL-13, IFN-gamma, IL-4 and IL- $6 .^{29,30}$ All of these modulators are involved in the development of allergic inflammation in asthmatics. ${ }^{28}$ In the present study, asthmatic patients homozygous for the minor $-4209 T>G$ allele exhibited higher FPR2 protein expression and less decrease of FEV1 fall rate after aspirin challenge. This data suggest that FPR2, a high-affinity ligand receptor for lipoxins and lipoxinA4 (LXA4) analogue, may exert protective effect against aspirin induced bronchospasm. Lipoxin A4 generation and lipoxin A4 receptor expression were found to be decreased in airway tissues of patients with severe asthma. ${ }^{31}$ Thus, downregulation of lipoxin and aspirin-triggered lipoxin may have additive effects on inflammatory reactions in the presence of low-level expression of the FPR2, as seen in AERD. 

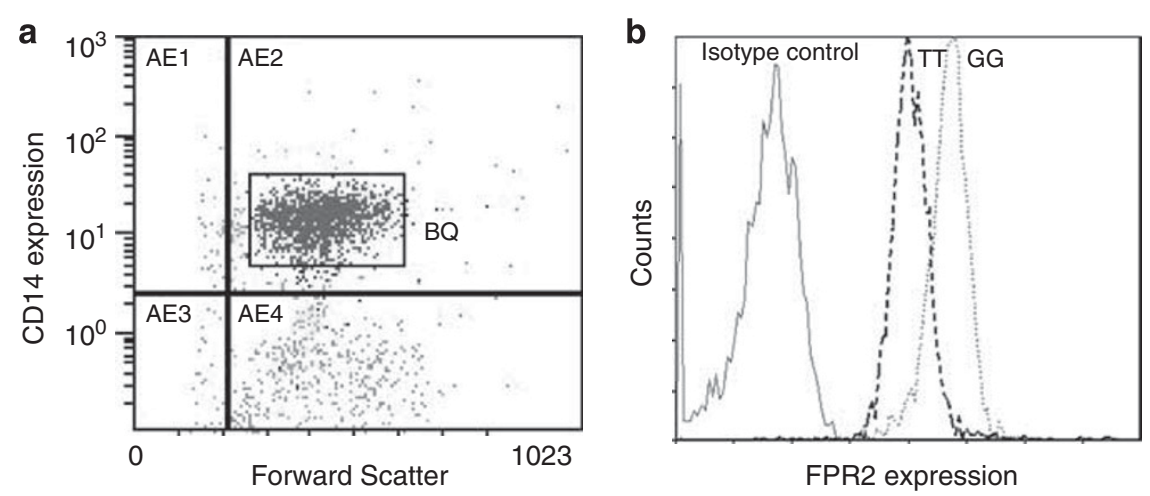

FPR2 expression
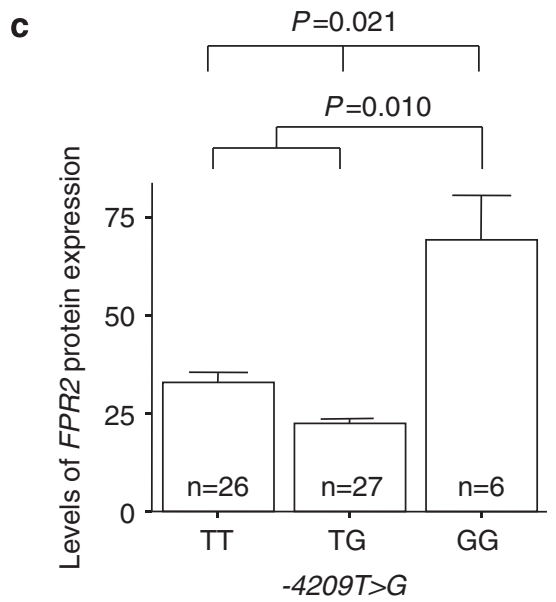

d

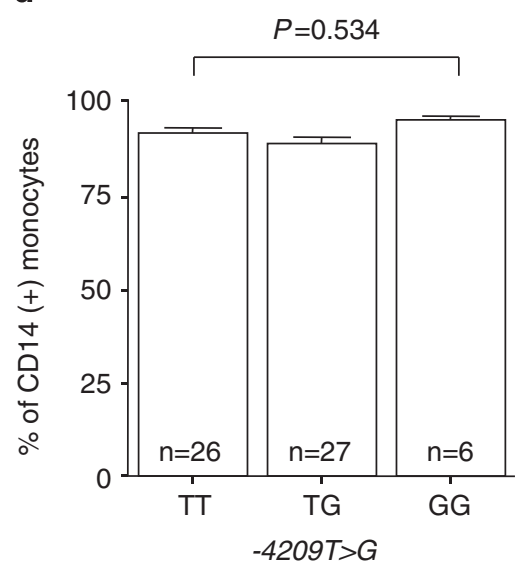

Figure 3 Flow cytometry analysis of formyl peptide receptor2 (FPR2) expression in peripheral blood cells in asthmatics. (a) To identify monocytes among peripheral blood cells, cells were gated by forward scatter and CD14 staining. Points inside the box represent CD14 (+) monocytes. (b) Histogram of FPR2 protein expression in CD14 (+) monocytes. Plot 1, isotype control; Plot2, -4209TT; and Plot3, -4209GG. (c) Mean levels of FPR2 protein expression per CD14 (+) monocyte from asthmatics with the -4209TT, TG and GG genotypes. (d) Percentage of CD14 (+) monocytes of each genotype exhibiting expression of FPR2. A full color version of this figure is available at the Journal of Human Genetics journal online.

a

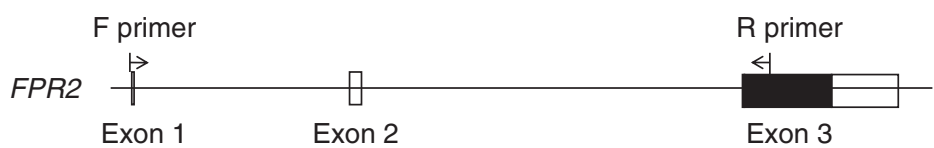

b FPR2 GAPDH

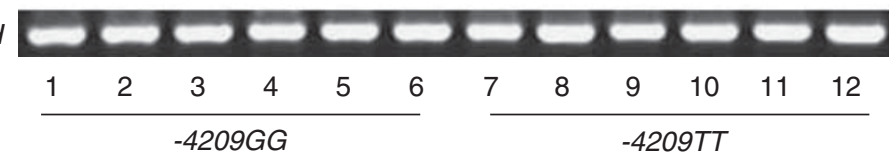

C

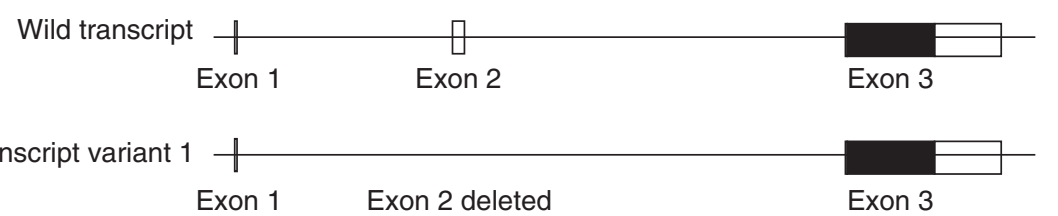

Figure 4 Comparison of formyl peptide receptor2 (FPR2) mRNA levels from its single-nucleotide polymorphisms (SNP) subtypes. (a) Organization of human FPR2 and diagram of RT-PCR primer. (b) RT-PCR Product size from Exon1 to Exon3 is 231 bp and alternative form of PCR Product size is 360 bp. PBMC containing T allele or G allele was harvested and FPR2 mRNA was measured using by RT-PCR. (c) The alternative form has a new transcript variant. 
In the flow cytometry analysis, we found that asthmatic patients homozygous for the rare $-4209 T>G$ allele exhibited higher FPR2 protein expression than patients with the common allele. These findings demonstrate that FPR2 protein expression may be dependent on the genetic function of the $-4209 T>G$ allele. It is well known that intronic SNPs can affect transcript processing through alternative splicing or producing RNA secondary structure. ${ }^{32-34}$ The FPR2 $-4209 T>G$ located in the second intron. Therefore, we have checked the presence of alternatively spliced forms of FPR2 by RT-PCR over exon 1 to exon 3. A 231-bp wild form and a new alternative form of $360 \mathrm{bp}$ were clearly visualized. The expression of the two forms of $F P R 2$ are obvious in the both genotypes of FPR2 $-4209 T>G$. This data indicate that the new alternative spliced variants may not be related with the genotypes of FPR2 $-4209 T>G$. However, we did not measure the m-RNA synthesis of the two forms of FPR2 using real time PCR. Further investigation is needed to better understand the genetic mechanism of the intronic SNP of FPR2 on the generation of the wild and the new-spiced variants of this gene.

Another explanation for the differential protein expression of FPR2 may be different rate of mRNA production, which depends on the secondary structure of mRNA. The secondary structure can be predicted with using mfold web server version 3.1. ${ }^{35}$ The secondary structure containing the $T$ allele of $-4209 T>G$ has a $\Delta G$ of $-150.59 \mathrm{kcal} \mathrm{mol}^{-1}$ and that with $\mathrm{G}$ allele has a $\Delta \mathrm{G}$ of $-150.00 \mathrm{kcal} \mathrm{mol}^{-1}$. These data indicate that synthesis rate of FPR2 mRNA may be not different according to the genotypes of $F P R 2-4209 T>G$. Further investigation is needed to better understand the genetic mechanism of the intronic SNP of FPR2 in aspirin induced asthma (AIA) and to clarify the molecular function of the new-spiced variants of this gene.

In conclusion, we genotyped 11 SNPs located within FPR2 and examined their associations with AERD. Logistic analysis showed that FPR2 $-4209 T>\mathrm{C}$ is associated with AERD. This association was further validated by showing that patients homozygous for the minor allele of FPR2 -4209T > C exhibit higher levels of FPR2 protein expression in CD14 positive peripheral blood monocytes compared with those having the common allele. These data indicate that the minor allele of FPR2 $-4209 T>G$ may have a protective role in the development of aspirin hypersensitivity in asthma through an increase in FPR2 protein expression in inflammatory cells. These results may be useful for the development of new methods to diagnose AERD and new therapeutic strategies for the control of aspirin hypersensitivity in asthma.

\section{ACKNOWLEDGEMENTS}

DNA samples were generously provided by the Soonchunhyang University Bucheon Hospital Biobank, a member of the National Biobank of Korea, supported by the Ministry of Health, Welfare and Family Affairs, Republic of Korea.

1 Stevenson, D. D. \& Szczeklik, A. Clinical and pathologic perspectives on aspirin sensitivity and asthma. J. Allergy Clin. Immunol. 118, 773-786 quiz 87-8 (2006).

2 Lee, R. U. \& Stevenson, D. D. Aspirin-exacerbated respiratory disease: evaluation and management. Allergy Asthma Immunol. Res. 3, 3-10 (2011).

3 Chang, H. S., Park, J. S., Jang, A. S., Park, S. W., Uh, S. T., Kim, Y. H. et al. Diagnostic value of clinical parameters in the prediction of aspirin-exacerbated respiratory disease in asthma. Allergy Asthma Immunol. Res. 3, 256-264 (2011).

4 Szczeklik, A. \& Stevenson, D. D. Aspirin-induced asthma: advances in pathogenesis, diagnosis, and management. J. Allergy Clin. Immunol. 111, 913-921 quiz 22 (2003).

5 Sanak, M., Simon, H. U. \& Szczeklik, A. Leukotriene C4 synthase promoter polymorphism and risk of aspirin-induced asthma. Lancet 350, 1599-1600 (1997).

6 Choi, J. H., Park, H. S., Oh, H. B., Lee, J. H., Suh, Y. J., Park, C. S. et al. Leukotrienerelated gene polymorphisms in ASA-intolerant asthma: an association with a haplotype of 5-lipoxygenase. Hum Genet. 114, 337-344 (2004).
7 Jinnai, N., Sakagami, T., Sekigawa, T., Kakihara, M., Nakajima, T., Yoshida, K. et al. Polymorphisms in the prostaglandin E2 receptor subtype 2 gene confer susceptibility to aspirin-intolerant asthma: a candidate gene approach. Hum. Mol. Genet. 13, 3203-3217 (2004).

8 Park, H. W., Shin, E. S., Lee, J. E., Kim, S. H., Kim, S. S., Chang, Y. S. et al. Association between genetic variations in prostaglandin E2 receptor subtype EP3 gene (Ptger3) and asthma in the Korean population. Clin. Exp. Allergy 37, 1609-1615 (2007).

9 Park, J. S., Chang, H. S., Park, C. S., Lee, J. H., Lee, Y. M., Choi, J. H. et al. Association analysis of cysteinyl-leukotriene receptor 2 (CYSLTR2) polymorphisms with aspirin intolerance in asthmatics. Pharmacogenet. Genomics 15, 483-492 (2005).

10 Kim, S. H., Choi, J. H., Park, H. S., Holloway, J. W., Lee, S. K., Park, C. S. et al. Association of thromboxane A2 receptor gene polymorphism with the phenotype of acetyl salicylic acid-intolerant asthma. Clin. Exp. Allergy 35, 585-590 (2005).

$11 \mathrm{Kim}$, S. H., Oh, J. M., Kim, Y. S., Palmer, L. J., Suh, C. H., Nahm, D. H. et al. Cysteinyl leukotriene receptor 1 promoter polymorphism is associated with aspirin-intolerant asthma in males. Clin. Exp. Allergy 36, 433-439 (2006).

12 Bisgaard, H. Pathophysiology of the cysteinyl leukotrienes and effects of leukotriene receptor antagonists in asthma. Allergy 56(Suppl 66), 7-11 (2001).

13 Park, J. S., Jang, A. S., Park, S. W., Lee, Y. M., Uh, S. T., Kim, Y. H. et al. Protection of leukotriene receptor antagonist against aspirin-induced bronchospasm in asthmatics. Allergy Asthma Immunol. Res. 2, 48-54 (2010).

14 McMahon, B. \& Godson, C. Lipoxins: endogenous regulators of inflammation. Am. J. Physiol. Renal. Physiol. 286, F189-F201 (2004).

15 Kantarci, A. \& Van Dyke, T. E. Lipoxins in chronic inflammation. Crit. Rev. Oral. Biol. Med. 14, 4-12 (2003).

16 Migeotte, I., Communi, D. \& Parmentier, M. Formyl peptide receptors: a promiscuous subfamily of $\mathrm{G}$ protein-coupled receptors controlling immune responses. Cytokine Growth Factor Rev. 17, 501-519 (2006).

17 Partida-Sanchez, S., Iribarren, P., Moreno-Garcia, M. E., Gao, J. L., Murphy, P. M., Oppenheimer, N. et al. Chemotaxis and calcium responses of phagocytes to formyl peptide receptor ligands is differentially regulated by cyclic ADP ribose. J. Immunol. 172, 1896-1906 (2004).

18 Bateman, E. D., Hurd, S. S., Barnes, P. J., Bousquet, J., Drazen, J. M., FitzGerald, M. et al. Global strategy for asthma management and prevention: GINA executive summary. Eur. Respir. J. 31, 143-178 (2008).

19 Nizankowska-Mogilnicka, E., Bochenek, G., Mastalerz, L., Swierczynska, M., Picado, C., Scadding, G. et al. EAACI/GA2LEN guideline: aspirin provocation tests for diagnosis of aspirin hypersensitivity. Allergy 62, 1111-1118 (2007).

20 Vreeland, W. N., Meagher, R. J. \& Barron, A. E. Multiplexed, high-throughput genotyping by single-base extension and end-labeled free-solution electrophoresis. Anal. Chem. 74, 4328-4333 (2002)

21 Hedrick, P. W. Gametic disequilibrium measures: proceed with caution. Genetics 117, 331-341 (1987).

22 Stephens, M., Smith, N. J. \& Donnelly, P. A new statistical method for haplotype reconstruction from population data. Am. J. Hum. Genet. 68, 978-989 (2001).

23 Nyholt, D. R. A simple correction for multiple testing for single-nucleotide polymorphisms in linkage disequilibrium with each other. Am. J. Hum. Genet. 74, 765-769 (2004).

24 Gwinn, M. R., Sharma, A. \& De Nardin, E. Single nucleotide polymorphisms of the $\mathrm{N}$-formyl peptide receptor in localized juvenile periodontitis. J. Periodontol. 70, 1194-1201 (1999).

25 Bao, L., Gerard, N. P., Eddy, R. L. Jr., Shows, T. B. \& Gerard, C. Mapping of genes for the human C5a receptor (C5AR), human FMLP receptor (FPR), and two FMLP receptor homologue orphan receptors (FPRH1, FPRH2) to chromosome 19. Genomics 13, 437-440 (1992).

26 Ye, R. D., Cavanagh, S. L., Quehenberger, O., Prossnitz, E. R. \& Cochrane, C. G. Isolation of a CDNA that encodes a novel granulocyte $\mathrm{N}$-formyl peptide receptor. Biochem. Biophys. Res. Commun. 184, 582-589 (1992).

27 Gao, J. L., Lee, E. J. \& Murphy, P. M. Impaired antibacterial host defense in mice lacking the N-formylpeptide receptor. J. Exp. Med. 189, 657-662 (1999).

28 Chen, K., Le, Y., Liu, Y., Gong, W., Ying, G., Huang, J. et al. A critical role for the g protein-coupled receptor mFPR2 in airway inflammation and immune responses. J. Immunol. 184, 3331-3335.

29 Gronert, K., Gewirtz, A., Madara, J. L. \& Serhan, C. N. Identification of a human enterocyte lipoxin A4 receptor that is regulated by interleukin (IL)-13 and interferon gamma and inhibits tumor necrosis factor alpha-induced IL-8 release. J. Exp. Med. 187, 1285-1294 (1998)

30 Chiang, N., Gronert, K., Qiu, F. H. \& Serhan, C. N. Lipoxin A4 receptor. Cytokine Reference 2000, 2219-2233 (2000).

31 Planaguma, A., Kazani, S., Marigowda, G., Haworth, O., Mariani, T. J., Israel, E. et al. Airway lipoxin A4 generation and lipoxin A4 receptor expression are decreased in severe asthma. Am. J. Respir. Crit. Care Med. 178, 574-582 (2008).

32 Pagani, F. \& Baralle, F. E. Genomic variants in exons and introns: identifying the splicing spoilers. Nat. Rev. Genet. 5, 389-396 (2004).

$33 \mathrm{Knight,} \mathrm{J.} \mathrm{C.} \mathrm{Regulatory} \mathrm{polymorphisms} \mathrm{underlying} \mathrm{complex} \mathrm{disease} \mathrm{traits.} \mathrm{J.} \mathrm{Mol.} \mathrm{Med.}$ 83, 97-109 (2005).

34 Kalnina, Z., Zayakin, P., Silina, K. \& Line, A. Alterations of pre-mRNA splicing in cancer. Genes Chromosomes Cancer 42, 342-357 (2005).

35 Zuker, M. Mfold web server for nucleic acid folding and hybridization prediction. Nucleic Acids Res. 31, 3406-3415 (2003).

Supplementary Information accompanies the paper on Journal of Human Genetics website (http://www.nature.com/jhg) 